\title{
A Review of the Tripartite Model Linking Associations between TQM, Organizational Learning, and Performance
}

\author{
Akram Hasan Aljaffan ${ }^{1}$ \\ ${ }^{1}$ DBA candidate, Swiss Business School, United Arab Emirates \\ Correspondence: Akram Hasan Aljaffan, DBA candidate, Swiss Business School, United Arab Emirates.
}

Received: May 19, 2017

doi:10.5539/ibr.v10n8p11

\author{
Accepted: June 19, $2017 \quad$ Online Published: July 4, 2017 \\ URL: https://doi.org/10.5539/ibr.v10n8p11
}

\begin{abstract}
This review aims to examine selected research articles that empirically investigated the relationship between Total Quality Management (TQM), Organizational Learning and Performance. The objectives of the current review are threefold. First, it aims to provide a comparative analysis regarding, findings, methodology, and dimensions, second, it explores the dimensions of the relevant constructs based on literature review, and Third, it compares the inferred concepts with those developed in the selected research studies. The current paper found a lack of conceptual clarity of the selected research studies' dimensions when compared with the conceptually developed ones based on expanded literature review, methodological issues and ill-defined practices during confirmatory factor analysis and unsatisfactory scales selection justification from a theoretical perspective. Recommendations for pertaining future research mainly include building a broader theoretical lens while developing the dimensions of TQM, organizational learning, and performance, enhanced confirmatory factor analysis reporting practices and embracing qualitative research methods that further investigate the tripartite model.
\end{abstract}

Keywords: TQM, total quality management, organizational learning, organizational performance, confirmatory factor analysis, dimensions, latent factor, organizational learning capability, structural equation modeling. validity

\section{Introduction}

This review aims to examine selected research articles that empirically investigated the relationship between Total Quality Management (TQM), Organizational Learning and Performance. The objectives of the current review are threefold. First, it aims to provide a comparative analysis regarding dimensions, findings, and methodology, second, to determine the appropriate conceptual dimensions of the relevant constructs based on literature review, and third, it compares the theoretical dimensions with those developed in the selected research studies. In spite of the scarcity of research that aims to investigate the relationships among TQM, Organizational Learning and Performance (Martínez-Costa \& Jiménez-Jiménez, 2009), the relatively growing number of published research articles that examined the tripartite model was facilitated by the popularity of the use of structural equation modeling (SEM) and factor analysis in the last 20 years. No robust theoretical perspectives appear to have driven the development of each construct's factors and the extent of their convergence with conceptual dimensions that define each of the three disciplines in an overarching manner. Furthermore, a literature gap crystallizes through the diversification of the developed dimensions for organizational learning (Lloria \& Moreno-Luzon, 2014), TQM (Zeitz, Johannesson, \& Ritchie, 1997, P. 416). Moreover, subjective performance constructs often lack proper scale validation (Shea, Cooper, de Cieri \& Sheehan, 2012, P. 509). Therefore, this review aims to investigate the dimensionality of the involved constructs at the conceptual level, and to analyze the proposed path analysis linking them together.

The current review recognizes the importance of research linking TQM, organizational learning and their effects on performance for the academe and practice equally. McAdam et al. (1998) conceptually examined the linkages between total quality and organizational learning contending that while both fields appear distinct, they shared common features. The study shed light on deficiencies for each discipline demonstrating the rationale to combine them to exercise a synergistic effect at a time where the distinct effects of TQM and organizational learning on performance have been extensively investigated. Furthermore, it contends that TQM has focused on efficiency while organizational learning underscored proficiency. Hence, it stresses on the existing gap in literature and 
industry in exploring approaches that combine both fields. Several scholars highlighted the pervading gap bet ween continuous improvement and organizational learning on both conceptual and empirical levels (Yoram, Rami, \& Zvi, 1997; Sun, Ho, \& Ni. 2008). Therefore, this review serves as a guide for appropriate research methodology and constructs dimensionality. In the same vein, it draws on the practical implications of its findings for the practitioners and scholars to stimulate the proposition of novelty frameworks to integrate both TQM and organizational learning creating a synergistic effect on performance.

At the outset, the current review sets out to evaluate the theoretical basis that links the three concerned fields and examine the dimensions/factors used as proxies to construct each discipline on the conceptual level. The review proceeds as follows: First, it examines selected research papers that empirically investigated the relationships within the triad "TQM-Organizational learning -Performance" concerning the findings, dimensions, and methodology. Second, a literature review of the conceptual dimensionality of each of the three constructs will follow, and finally, the findings will be cross-validated with the proposed factors within the selected articles. The objectives of the current review are:

- What are the relevant research results that involve the nature of the relationships among TQM, organizational learning, and performance?

- What is the quality of the methodology used while developing the research designs and methods of the selected articles involving the tripartite model?

- What are the most appropriate and comprehensive dimensions for each of the constructs: TQM, organizational learning, and performance?

- What are the conceptual linkages between TQM and organizational learning?

\subsection{Theoretical Framework}

While aiming to seek an understanding of the conceptual background that shapes the tripartite model, this review suggests an existing performance management and measurement framework named TPS. According to Rampersad (2003), TPS (total performance scorecard) conceptualizes the interplay of experiential learning and TQM emphasizing three essential axioms: personal and organizational competence development, learning and improvement which all serve as the primary purposes of the proposed theory. Furthermore, while TPS principal functions intersect at knowledge zone, it encompasses six principles: Focus on Customer satisfaction, passion, and enjoyment, consistent personal and organizational objectives, ethical and fact based behavior, process orientation and concentration on a consistent improvement, learning, and de velopment. Each principle hybridizes components of TQM and experiential learning. For instance, the notion of PDCA (Plan, do, check and act) learning as a tool that drives learning during continuous improvements processes sustains considering errors as opportunities. This philosophy merged TQM with organizational learning concepts by combining action learning with quality practices.

Drawing on the fundamental principles of TPS framework, customer focus, continuous improvement, employees' engagement and top management support serve as pillars to the TQM concept while experiential learning derives knowledge evolution. In the same vein, efficiency and effectiveness of the structures, processes, and stakeholders (employees and customers, supplier) shape the performance domain. Consequently, theses conclusions shall direct the critical analysis of the subsequent dimensional literature review for TQM, organizational learning, and performance. TPS framework entails a behaviorally based learning that state that learning occurs only through a change in behavior. It also emphasizes that learning starts with individuals, which corresponds with the ontological views of Nonaka's (1994) theory of knowledge creation. Furthermore, it accounts for the types of learning exploration and exploitation that have been extensively studied by March (1991). Finally, the principle "process orientation" resonates with the learning sub-processes of (Crossan, Lane \& White, 1999).

The paper's structure proceeds as follows: Section one provides an overview of the findings and methodology review of the selected articles. Section two develops the relevant dimensions based on literature review of existing research using the theoretical framework (Total performance Scorecard). Finally, the review paper discusses the findings and how they relate to the proposed models in the selected publications.

\section{Method}

A simultaneous search for the terms TQM, organizational learning, and performance was conducted using Business Source Complete, Emerald Insight, JStore, and Elsevier limiting the search results to Business as a subject and English publications and refining the results to include the term "empirical research" reveals twenty results. After a careful examination of the abstracts, eight research papers were selected. While all selected articles developed TQM as an exogenous variable, the endogenous variables included varied forms of 
organizational learning (organizational learning capacity) and performance constructs (financial, innovation, business, market and organizational performance).

\subsection{Overview of the Articles' Findings}

Table 1 summarizes the seven selected articles which constitute the scope of the current review along with the affected industries. While all chosen papers studied TQM as an independent or exogenous variable, organizational learning and performance, as endogenous variables, were researched in different variants, for example, Financial, non-financial business and organizational performance, and organizational learning capability (OLC) and learning orientation. Other research articles included additional variables e.g. business innovativeness (Akgün, Imamoglu, Keskin \& Kocoglu, 2014). The most common control variables were respondent seniority, position and age, firm, size and industry type. In the context of the current review's purview, all the selected articles demonstrated empirically that TQM and any variant of organizational learning positively correlated with performance. The total mediating effect of organizational learning or its related variable was mostly verified with statistical significance except for one study which suggested a partial mediating effect (Hung, Lien, Yang, Wu, \& Kuo, 2011).

Table 1. Selected research articles and their findings

\begin{tabular}{ccc}
\hline Article & Control variables & Main findings \\
\hline $\begin{array}{c}\text { (Hung, Lien, Yang, Wu, } \\
\text { \& Kuo, 2011) }\end{array}$ & $\begin{array}{c}\text { Total sales volume, the size of the } \\
\text { organization, age of firms, and sub-type of } \\
\text { industrial classification in high-tech industries. }\end{array}$ & $\begin{array}{c}\text { TQM affects positively organizational learning } \\
\text { and Innovation performance. }\end{array}$ \\
$\begin{array}{c}\text { Organizational learning, acting as a partial } \\
\text { mediator, affects Innovation performance } \\
\text { positively. }\end{array}$ \\
\hline
\end{tabular}

TQM affects positively organizational learning capability (OLC) and business innovativeness.

OLC positively impacts business innovativeness.

Firm size
(Akgün et al., 2014) Manufacturing type and respondent position.

Business innovativeness affects financial performance.

OLC and business innovativeness mediate

TQM-financial performance constructs.

\begin{tabular}{|c|c|c|}
\hline $\begin{array}{c}\text { (Mahmood, Qadeer, and } \\
\text { Ahmad,2015) }\end{array}$ & Firm's age and size & $\begin{array}{l}\text { TQM and OLC affects performance positively } \\
\text { Organizational learning mediates TQM and } \\
\text { OLC relationship. }\end{array}$ \\
\hline
\end{tabular}

(Lee \& Lee, 2014) Gender, educational attainment, position, industry type and seniority

Both TQM and organizational learning affect positively business performance while

organizational learning plays the role of a mediator

\begin{tabular}{cl}
\hline (Jiménez-Jiménez et al., & $\begin{array}{l}\text { The age, size (number of employees), and the } \\
\text { degree of internationalization of the company }\end{array}$ \\
\hline
\end{tabular}

(Lam et al., 2011)

Position, company size, Certification status

Exploration capability positively affects organizational performance

TQM is positively related to both learning orientation and market performance.

Mediating effect of learning orientation was insignificant

(Martínez-Costa \&
Jiménez-Jiménez, 2008) Firms size, sector and performance

TQM affects positively organizational learning and performance.

Organizational learning affects performance. Organizational learning and performance are

(Martínez-Costa \& Jiménez-Jiménez, 2009)

sector, age, and size of firms positively correlated.

TQM and organizational learning are related.

TQM affects performance via a direct and indirect effect through organizational learning

\subsection{Dimensionality}

Table 2 shows the factors that were validated using confirmatory factor analysis for each construct. Most of the studied research papers developed diversified models to represent TQM, organizational learning, and performance following a relatively satisfactory conceptual review of relevant literature. The following studies proposed a singleton dimensional approach for at least one construct. For example (Mahmood et al., 2015) for organizational learning capability, (Lam et al., 2011) for market performance and organizational learning, (Martínez-Costa \& Jimenez-Jimenez,2008, 2009) for TQM and performance, Jiménez-Jiménez and (Martínez-Costa, 2009) for TQM and organizational learning. While TQM dimensions ranged from one to seven, the most common factors among the multidimensional models were; customer focus (involvement), continuous improvement, process management and top management support. Organizational learning construct expressed 
the broadest dimensional variation with a range of two to four factors. It is worthy to stratify these constructs based on the technical and social perspective that often predominate the conception of organizational learning or any of its related fields (OLC, Learning orientation). The technical view entails the identification, coding, storage, and analysis of information while social view stresses on the people sense making on how and what to learn through experiences (Easterby-Smith, Araujo \& Burgoyne, 1999). Having said that, most of the proposed organizational learning constructs rather undergird aspects of the social view while Martínez-Costa \& Jimenez-Jimenez (2009) developed a technical view of the discipline drawing on Huber's (1991) organizational learning stages.

Most of the selected articles adopted the subjective measurement (perceived by key informants e.g. executives, CEO, directors, and managers or employees). Performance factors were mostly financial (profitability, revenue) with one or more dimensions or non-financial (market share, customer satisfaction, employee productivity, quality product). Other scholars classified performance as either objective or judgmental (Mahmood et al., 2015).

Table 2. Factors/ Dimensions

\begin{tabular}{ccc}
\hline & Factors / Items & Performance \\
\hline TQM & Organizational learning/ OLC & \\
\hline Top management support, employee & & \\
involvement, & Learning culture and learning & product innovation, process innovation, and \\
continuous $\begin{array}{c}\text { improvement, and customer } \\
\text { focus }\end{array}$ & strategy & ovanizational innovation \\
16 items & 9 items & \\
(Hung et al.,2011) & & \\
\hline
\end{tabular}

Process management, leadership, customer focus, strategic planning, information analysis and people management. 24 items (Akgün et al., 2014)
OLC Managerial commitment, systems perspective, openness and experimentation, knowledge transfer and integration 13 items
Financial performance:

Return on investment. Gross margin Earnings 3 items

\begin{tabular}{|c|c|c|}
\hline $\begin{array}{l}\text { Top management support, employee } \\
\text { involvement, continuous improvement, } \\
\text { and customer focus } \\
41 \text { items } \\
\text { (Mahmood, Qadeer \& Ahmad, 2015) }\end{array}$ & $\begin{array}{l}\text { One dimension } \\
\text { Ten items }\end{array}$ & $\begin{array}{c}\text { Organizational performance: objective } \\
\text { performance and judgmental performance. } \\
11 \text { items }\end{array}$ \\
\hline $\begin{array}{l}\text { Customer focus, continuous } \\
\text { improvement, process management and } \\
\text { service culture } \\
19 \text { items } \\
\text { (Lee \& Lee, 2014) }\end{array}$ & $\begin{array}{l}\text { Learning orientation, information } \\
\text { orientation, and team orientation } \\
15 \text { items }\end{array}$ & $\begin{array}{l}\text { Financial performance (total premium } \\
\text { revenues, profit after tax, and cost } \\
\text { improvement) and non-financial } \\
\text { performance (market share, customer } \\
\text { satisfaction, and employee productivity) } \\
\text { Ten items }\end{array}$ \\
\hline $\begin{array}{c}\text { Top management support, quality } \\
\text { information, process management, } \\
\text { product design and workforce } \\
\text { management, supplier involvement and } \\
\text { customer involvement } \\
14 \text { items } \\
\text { (Jiménez-Jiménez et al., 2015) }\end{array}$ & $\begin{array}{l}\text { Exploration and exploitation } \\
\text { learning capabilities } \\
\text { Ten items }\end{array}$ & $\begin{array}{l}\text { EFQM four results criteria, four dimensions } \\
\qquad 16 \text { items }\end{array}$ \\
\hline $\begin{array}{c}\text { Leadership, customer focus, strategic } \\
\text { planning, human resource management, } \\
\text { information and analysis and process } \\
\text { management } \\
25 \text { items } \\
\text { (Lam et al., 2011) }\end{array}$ & $\begin{array}{l}\text { One dimension: } \\
\text { learning orientation } \\
\quad \text { Six items }\end{array}$ & $\begin{array}{l}\text { One dimension: } \\
\text { market performance } \\
\text { Six items }\end{array}$ \\
\hline $\begin{array}{c}\text { One dimension } \\
\text { Seven items, } \\
\text { (Martínez-Costa \& Jiménez-Jiménez, } \\
\text { 2008) } \\
\end{array}$ & $\begin{array}{l}\text { Three dimensions: Individual, } \\
\text { group and organizational learning } \\
18 \text { items }\end{array}$ & $\begin{array}{l}\text { One dimension } \\
\text { Five items }\end{array}$ \\
\hline $\begin{array}{c}\text { One dimension } \\
\text { Six items } \\
\text { (Martínez-Costa \& Jimenez-Jimenez, } \\
\text { 2009) }\end{array}$ & $\begin{array}{c}\text { Four dimensions: } \\
\text { knowledge acquisition } \\
\text { Knowledge internalization and } \\
\text { organizational memory } \\
25 \text { items }\end{array}$ & Four items, one dimension. \\
\hline
\end{tabular}




\subsection{Methodology/Method Analysis}

All the selected articles performed, for the three constructs, first and second-order confirmatory factor analysis (CFA) and SEM except the research conducted by Mahmood, Qadeer and Ahmad (2015) which used hierarchical regression. It is worthy to mention the superiority of SEM over regression while dealing with latent variables. The former accounts for error variance allowing theory -driven measurement errors to covary. In the same vein, as being the second generation multivariate analysis method, SEM allows simultaneous analysis of all variables contrary to multiple regression methods (Brown, 2015). Some of the research has focused on multi-industrial firms (Akgün et al., 2014; Jiménez-Jiménez, Martínez-Costa, Martínez-Lorente \& Rabeh, 2015; Martínez-Costa \& Jiménez-Jiménez, 2008; 2009) and services industries (Lam et al., 2011). Others focused on a single industry such as textile (Mahmood et al., 2015), service industry (Lam et al., 2011), insurance (Lee \& Lee, 2014) and high technology (Hung et al., 2011).

\subsubsection{Scale}

Most of the instrumental surveys were self-administered, or interview-based multi-items questionnaires addressed to key informants using individual measurement for performance except the research conducted by (Lee \& Lee, 2014) which surveyed regular employees from 17 insurance companies. The majority of the selected articles ran pilot studies for wording adjustments, industry- specific scale customization or validation purposes. Referring to Appendix A, five or six points Likert -scale was the most widely used measurement scale. While primarily relying on previously validated scales, the questionnaires comprised of thirty to fifty items on average. The response rate exhibited a significant variability as high as $89.47 \%$ (Lee \& Lee, 2014) and low as (Hung et al., 2011).

\subsubsection{Technique Analysis}

Most of the selected articles used structural equation modeling (SEM) using a variety of statistical software (Lisrel, Amos, EQS). The sample size significantly affects the construct validity and the significance of the results where it is recommended to have 200 as sample size or 20 cases per parameter with a minimum of five to ten cases per parameter (Kline, 2011). The need for a bigger sample size increases with the complexity of the model and with further mediation analysis. The number of the participating key informants ranged from one to four (Jiménez-Jiménez et al., 2015) per organization. It is worthwhile to mention that perceptual measures probe the performance broader than objective measures through both financial and non-financial measures (Wall et al., 2004). However, the latter assumption should extend to a rigorous scale reliability and validity. In fact, Richard, Devinney, Yip and Johnson, 2009) report that while the use of perceptual measurement by key informants is increasingly gaining popularity in the management field, the need for validity and reliability studies is growing.

An examination of the selected articles' methodology found rare analysis of the normality of multivariate data which is an assumption for SEM. According to Brown (2015, pp. 137-138), the normality and detection of outliers for both univariate and multivariate data should precede CFA and SEM. Principle component and Varimax were performed in (Lee \& Lee, 2014), this study also tested colinearity using VIF ( Variance inflation factor). A VIF value above ten means serious problem of co-linearity (Gujarati, 1995), in the same vein, the study ( Mahmood et al., 2015) has not tested it despite that multi-colinearity is a breach of multiple regression. Other recommendations include the use of various indices to test the model fit such as (GFI, CFI, TLI, RMSEA, SRMR), the transparent reporting of the items factors loadings and any correlation between factors or between measurement errors).

In parallel lines, modification indices and standardized residuals analysis to examine localized points of ill fit should also be reported. An example of tests for multivariate outliers is Mahalanobis distance (Schinka, Velicer, Wayne, Weiner \& Irving, 2003). Referring to SEM, the model identification dictates that the number estimated parameters ( item variances and covariances) must be greater or equal to the number of freely estimated model parameters ( factors loadings, factors variances and covariances and the errors variance-covariance) according to Brown (2015, P. 61). All the studies that used CFA used maximum likelihood minimization function as a method of estimation which is the most widely used method that resides on the variance- covariance concept.

While drawing on the stringent need for a robust scale reliability and validity, Bontis, Crossan, and Hulland (2002) recommend the following steps to ensure reliable and valid measures:

- Overarching item development.

- Pilot study evaluation of the questions and subsequent instrument revision

- Completion of the research using the adjusted questionnaire 
The same study points out perceptual measurements are adequate because they reflect real perceptions in the relevant context making the methodological individualism the only means to study social sciences (Konecni, 1977 in Bontis et al., 2002, p. 457). Building on that assumption, General Managers were used as key informants. They are expected to have comprehensive knowledge of the firm's operations, strategy, and performance (Weerawardena, O'Cass, \& Julian, 2006). In that context, having more than one key informant in the research design would result in more assurance of the responses authenticity especially if the responses across each organization are compared to each other.

Any alteration in the scale would jeopardize its pre-established validity and reliability requiring the necessity to perform exploratory factor analysis. This issue applies in particular to the following (Lee \& Lee, 2014; (Martínez-Costa \& Jimenez-Jimenez, 2008, 2009) and (Jiménez-Jiménez et al., 2015) which either combined items from different previous scales or modified them. A minority of papers ran exploratory factor analysis when there was a necessity. Few studies performed The Kaiser-Mayer-Olkin (KMO) measure of sampling adequacy test (Kaiser, 1974) which measures sample adequacy for factor analysis, and Bartlett's (1950) Sphericity test that evaluates the suitability of each item ((Lee \& Lee, 2014). Additionally, a commendable practice of performing common method variance in the case of use of one key informant per organization (Podsakoff, MacKenzie, Lee \& Podsakoff, 2003) ascribes to the research of Martínez-Costa and Jimenez-Jimenez (2009).

\subsubsection{Model Fit}

In the frame of SEM and CFA, the evaluation of the extent of model fit requires estimations of model fit indices (absolute, relative, parsimonious and non- centrality based). The most commonly reported indices are: The $\chi 2$ goodness-of-fit statistic, the root-mean-square error of approximation (RMSEA), comparative fit index (CFI), the goodness of fit index (GFI) and Tucker-Lewis index (TLI). The $\chi 2$ goodness-of-fit statistic evaluates the fit between the data and the implied model. According to Chen (2007), RMSEA measures the difference between the observed covariance matrix per degree of freedom and the model implied covariance matrix while CFI is an incremental fit index that measures the extent of the superiority of the proposed model over the al ternative independent model.

Besides RMEA, the indices (CFI, TLI, TLI, GFI, and AGFI) should be greater than the recommended 0.90 threshold level (Hoyle \& Panter, 1995; Jöreskog \& Sörbomm, 1996) while RMSEA normally ranges between zero and one. MacCallum, Browne, and Sugawara (1996) classified RMSEA values into excellent (0.01), good (0.05) and mediocre (0.08). According to Brown (2015), AGFI, being an adjusted form of GFI serves as a better index compared to its counterpart. When sample size is high, $\chi 2$ goodness-of-fit statistic tends to be significant whereas in the case of CFA it should be insignificant as it tests the null hypothesis that the difference between the predicted and actual estimates is zero. A better indicator is to report $\chi 2 / \mathrm{df}$ (chi-square divided by its degree of freedom) which should be less than three (Bagozzi \& Yi, 1988). Few reported indices in the selected papers were found beyond the acceptable ranges, for instance, the second order CFA analysis of TQM model in the study (Hung et al., 2011, p. 217) shows RMSEA value equals to an extreme value of (0.11). It is worthy to mention that the various fit indices validity and their thresholds remain controversial. Cangur and Ercan (2015) found that $\chi 2 / \mathrm{df}, \mathrm{RMSEA}$, and CFI are the least affected indices regardless of the estimation technique and sample size. This evidence suggests the significance of these indicators as critical indices for the construct validity.

\subsubsection{Localized Points of Ill Fit}

Modification indices (MI) which have often been overlooked or not reported, compute for each fixed parameter in the construct how much the overall model chi-square would decrease if the fixed or constrained parameter is allowed to be freely estimated, such analysis has rarely been reported in the selected articles (Brown, 2015, P. 99). None of the chosen articles proclaimed the dynamics of model modification based on MI especially when adding errors covariance within the same factor. Furthermore, Brown (2015) argues that any measurement errors covariance constraints should be supported with a priori theoretical justification.

Another layer of analysis which is an often not reported by scholars and especially in the pool of the selected articles is the standardized residuals standing for the difference between the sample and model implied matrices. A cutoff point for $5 \%$ significance is two.

In efforts to adjust the model fit, the practice of items deletion, which is frequently conducted when the factor loading is below 0.5, should be reported with an indication of exact deleted item(s) ( Brown, 2015). The research carried out by (Lee \& Lee, 2014) reported it showing a good practice. However, it did not justify with a priori theory- driven arguments (Brown, 2015). 


\subsubsection{Scale Reliability}

Reliability of the measures is often calculated with Bagozzi and Yi's (1988) composite reliability index (CRI) and with Fornell and Larcker's (1981) average variance extracted index (AVE). For all the measures, both indices should be greater than 0.6 for the composite reliability and 0.5 for the average variance extracted (Bagozzi \& Yi, 1988; (Fornell \&Larcker, 1981). While Mahmood et al.,( 2015) tested the scale reliability using only Cronbach alpha, all the other selected studies used AVE and CRI additionally. The scale reliability constitutes a crucial factor in the viability of the scale development. Failure to demonstrate a reliable scale precludes proceeding further to validity as it tests the consistency of the measures.

\subsubsection{Discriminant Validity}

Also known as divergent validity, it tests the degree of genuine autonomy of measures when they are supposed to be conceptually unrelated. While accounting that discriminant validity can be assessed by three methods: Q-sorting, AVE analysis and chi-square difference test (Bertea \& Zait, 2011), Akgün et al., (2014) performed extensive discriminant validity tests using the chi-square difference tests between different models that differed by their level of constraining between factors. Similarly, (Jiménez-Jiménez et al., 2015; 2008) also performed AVE analysis and another method based on confidence interval for latent factors correlation ( cut off point $=1$ ). Most of the studies in hand showed discriminant validity using the chi-square difference test, but none triangulated discriminant validity tests.

\subsubsection{Convergent Validity}

The convergent validity evaluates the degree of the scale measures to be related while they are supposed to be so conceptually. According to Fornell and Larcker (1981), convergent validity was evaluated for the measurement model based on two criteria. (1) Each indicator factor loadings should be higher than 0.50 for acceptability. (2) The average variance extracted (AVE) of each construct should be at least 0.5 or above. It is concluded that the selected articles showed a relatively acceptable validity and reliability of their proposed scales.

In the next section, the dimensions of each of the involved constructs will be reviewed from relevant literature while using the TPS principles and related theoretical perspectives as criteria for analysis. The purpose here is to denote a parsimonious dimensional model for each construct that fits within the TPS approach.

\subsection{Literature Review of the Constructs Dimensionality}

\subsubsection{TQM}

To appropriately dimensionalize TQM, it is important to broadly define it taking account of its underlying concepts and principles. According to several scholars (Dean \& Bowen, 1994; Lau \& Anderson, 1998), TQM is a performance and management philosophy that blossomed in the US as a result of declining competitiveness in US economy at the expense of the successful growth of Japanese companies in the motor industry in the 1980s. Juran (1988) argues quality focuses on customers' needs and expectations while Baldwin and Johnson, (1996) contend TQM promotes differentiation of organizations from an innovation perspective. TQM is considered the most convenient continuous improvement strategy to corroborate organizational development (Lin \& Ogunyemi, 1996). Other scholars link TQM as a source of competitive advantage sustainability (Munizu, 2013; Terziovski \& Samson, 1999). Evans and Lindsay (1996) indicated that TQM is a quality management approach that aims to improve effectiveness and efficiency of organizations. The old definition that is technically driven such as the one by Crosby (1996) who connotes quality as "conformance to requirements or specifications" is increasingly replaced with a broader concept in management. Following on that new perspective, TQM concept clusters into three levels: technical hard, social soft and the interaction of both (Prajogo \& Sohal, 2006). The technical part focuses on improvement of goods and services based on production and process, while the social soft concentrates on the activities related to human resources management. Unfortunately, despite the shift towards considering TQM from a system's thinking approach, eighty percent of institutions fail to produce benefits while implementing TQM in practice (Bak, 1992) suggesting the need to re-engineer TQM or blend it with other concepts.

\subsubsection{TQM Dimensions}

The proposed dimensions for TQM exhibit a significant amount of variation. Furthermore, another challenge in developing proper dimensions stands in difficulty in identifying the elements of TQM due to inconsistency in research (Hoang, Igel, \& Laosirihongthong, 2006). In a study ( Al Ghamdi, Aziz, Yusoff, \& Mustafa, 2016) scholars proposed the following dimensions: (top management commitment, training, supplier management, strategic quality planning, customer focus, employee involvement, product and service design, process management and quality culture). 
In another study (Dubey \& Gunasekaran, 2015) and while studying the impact of soft TQM on performance, they constructed four dimensions for TQM: human resource, quality, culture, motivational leadership and relationship management. Demirbag . Tatoglu, Tekinkus, and Zaim (2006) analyzed the relationship between TQM and performance (both financial and non-financial) in SMEs in the textile industry empirically. They used seven dimensions for TQM: quality data and reporting, role of top management, employee relations, supplier quality management, training, quality policy of top management, and process management.

Flyyn, Schroder, and Sakakibara (1994) identified seven factors for TQM: top management support, quality information, process management, product design, workforce management, supplier involvement, and customer involvement. Anderson, Rungtusanatham, and Schroeder (1994) reduced Deming's 14 points (1986) into eight factors for quality management practices: visionary leadership, internal and external cooperation, learning, process management, continuous improvement, employee fulfillment and customer satisfaction. Black and Porter (1996) identified the following factors for TQM using the Malcolm Baldrige Award criteria: "Corporate quality culture", "strategic quality management", "quality improvement measurement systems", "people and customer management", "operational quality planning", "external interface management", "supplier partnerships", "teamwork structures", "customer satisfaction orientation", and "communication of improvement information".

Ahire and Golhar (1996) identified 12 factors for TQM: supplier quality management, supplier performance, customer focus, statistical process control usage, benchmarking, internal quality information usage, employee involvement, employee training, design quality management, employee empowerment, product quality, and top management commitment. According to Thorpe and Holloway (2000), ISO 9000 defines eight principles for quality management: Customer focus, leadership, involvement of people, process approach, system approach to management, continual improvement, factual approach to decision-making and mutually beneficial supplier relationships. Dean and Bowen (1994) proposed three dimensions for total quality management: teamwork, continuous improvement and customer focus which are common in most quality frameworks. Mosadeghrad (2015) developed and validated dimensions of TQM based on an empirical study conducted in Iran. He developed based on extensive literature review 15dimensions for TQM (ten enablers and five results). The same paper found high correlations between TQM construct and organizational performance. Employee management, information management, customer management, process management, and leadership were the strongest significant predictors of organizational performance. TQM has been found to encompass the following practices: leadership, strategic planning, customer focus, information and analysis, people management, and process management. (Prajogo, Power, \& Sohal, 2004; Terziovski \& Samson, 1999). Prajogo, Power, and Sohal (2004) explored the manufacturing industry firms by using the following six dimensions to construct TQM; leadership, strategic planning, customer focus, information four dimensions: top management support, employee involvement, continuous improvement, and customer focus. Terziovski and Samson (1999), who argue that categories of leadership, people management, and customer focus are the strongest significant predictors of organizational performance.

The diversity of the proposed dimensions in research creates a challenge in the methodology selection of the appropriate dimensions that best represent TQM. In the light of suggesting dimensions that are inclusive in the TPS core principles (Rampersad, 2003) and drawing on the canonical belief that TQM is a management philosophy (Dean \& Bowen, 1994; Lau \& Anderson, 1998), the dimensions that are solely technical driven are discarded. Some dimensional models propose extensively overlapping concepts such as process management, quality culture, and training which are inclusive in continuous improvement dimension.

Zairi (2013) stated that most of the quality gurus (Deming, Crosby, Feigenbaum, and Juran) focused on customer focus and continuous improvements as inextricable dimensions of quality. Further, He contends that Crosby's principles approach in quality management as putting great emphasis on the employees' attitudes and behaviors in managing quality "employees management" and top management view of quality which reflected through" top management support" to the workforce. Deming (1986) emphasized the crucial role of statistical and quality control giving rise to the importance of the dimension "information management." The aforementioned justifications conclude that the most widely accepted dimensions are continuous improvement, information management, employee's management, top management support and customer focus. This proposition accounts for the technical aspect of TQM which deal with quality tools and data management while additionally considering the managerial aspect of TQM; the latter includes stakeholders management (customers and employees) and top management commitment. The notion of considering both the technical and managerial aspects of TQM dwindled in most of the chosen papers. Just as one needs three dimensions to calculate the volume of an object, the proposed quality dimensions are inclusive of the TPS framework that holds the conceptual underpinnings of the tripartite model linking TQM, organizational learning and performance. 


\subsubsection{Organizational Learning}

\subsubsection{Learning Models}

While aiming to develop dimensions for organizational learning, it is crucial to investigate and explore the learning models that shaped the organizational learning field. As several learning models have been proposed, the author finds it useful to distinguish between the theories that stem from the technical or social view of organizational learning. It is worthy to underscore that Nonaka's SECI model (1994) and Blackler's (1995) framework embrace the technical view of learning While Trussler's building blocks for knowledge management (1998) and Their's model for a learning organization (2000) adopt the social view. Other models focus on the behavioral aspects of learning on individual, team, and system wide such as Senge (1992), Baiyin, Watkins, \& Marsick (2003) and Ortenblad (2015). The following section briefly discusses relevant learning theories for organizations whose breadth bounded organizational learning premises.

\subsubsection{SECI Model}

SECI Model (1994) includes Socialization, Externalization, Combination, and Internalization. This model focuses on expounding the possible conversions between different types of knowledge while specifically focusing on tacit and explicit knowledge. Socialization is concerned with the transfer of tacit among two or more people. On the other hand, externalization involves the transfer of tacit to explicit knowledge. "Combination" stage is the accumulation of explicit knowledge while internationalization transforms explicit knowledge to tacit knowledge which requires reiterated practice.

\section{a. Blackler model}

Blackler (1995) criticized SECI model stressing that the learning is collective and not individual and proposed the following stages for knowledge transfer:

- Embrained: Cognitive skills

- Embodied: Tacit knowledge as being action oriented

- Encultured: This dimension means that knowledge has become socialized and there is a consensus among people sharing it.

- Embedded knowledge: this is the knowledge that is implicit and intrinsic to routines and processes

- Encoded knowledge: this is the knowledge that translates through symbols and signs like policies and regulations.

This model demurred the role of individuality in the organizational learning which contradicts the formerly discussed model by Nonaka (1994). It also links competence of tacit knowledge with action which dictates "learning by doing" concept. While this model differentiates between routine based knowledge (intrinsic) from policy based knowledge (symbolic), this distinction appears puzzling; it manifests the often-cited conflict between the espoused and the actual beliefs of individuals which are the core assumption of double loop learning (Argyris \&Schon, 1978)

\section{b. Trussler model}

Trussler model (1998) differentiates between organizations based on the level of engagement in solving familiar or novel problems. The focus on solving novelty problems dictates innovation and teamwork while the focus on daily problems dictates relying on knowledge-based technologies and procedures from one side and human resource development on the other.

Trussler (1998) expounds the concept of organizational learning thereby providing a broader conceptualization of the underpinnings that holds successful organizational knowledge management. His overarching model construes organizational learning as the product of the interplay between leadership, culture, support, technology and continuous improvements.

Furthermore, he argues that any organization seeking to become a learning firm must reflect on the following questions:

1. What type of knowledge is most important to focus on and what are its benefits in business?

2. Which processes, routines, and tasks are likely to be affected by efficiency, effectiveness perspectives?

3. What is the best learning strategy (personalization or codification) to embrace as a means to an end? 


\section{c. Their model}

Their's model (2000) in (Neve, 2015) developed a model that sets out what is needed to be learned emphasizing the role of the customers' needs and expectations, market competition and the product itself. Their stresses the need for organizations to explore the individual at work and his or her psychological state (ability to learn, collaborate, communicate) as this drives the learning; he stresses the impact of organizational structures (hierarchy, formalization) on the learning process. Finally, he emphasizes the role of the leader's role. This model takes into account the macroeconomic perspective and the industry's competitiveness as influential factors that affect organizational learning.

\section{d. Senge Model}

Senge (1992) identified five components for learning organizations which are: personal mastery, mental models, shared vision, team learning and system thinking. The author notes that this model entails three levels of learning individual, team and organizational while at the same time it credits the significance of vision as a strategic element of organizational learning success. Mental models which are best known as schemas represent individual beliefs, assumptions, and claims that are culturally developed during experimentation.

\section{e. Baiyin, Marsick and Watkin Model}

Baiyin, Marsick, and Watkin (2004) proposed seven dimensions for organizational learning: Continuous learning, inquiry and dialogue, team learning, embedded system, empowerment, system connection and strategic leadership. This model undergirds on the interactions between individuals and the extent of their motivation and empowerment.

\section{f. Ortenblad Model}

Ortenblad (2015) proposed an integrated model consisting of four dimensions: learning at work, organizational learning, the climate for learning and learning structure. This model offered a parsimonious interpretation of the concept of organizational learning that highlighted the importance of the learning structures (knowledge management systems) and the learning environment which is integral to organizational culture.

\subsubsection{Dimensions of Organizational Learning}

Upon examining the literature, while a plethora of dimensions has been suggested to proxy organizational learning, multi-dimensionality often ascribes to the proposed constructs. Based on the importance in the development of a validated, consistent measurement instrument for organizational learning (Easterby-Smith \& Lyles, 2011), the author critically examined several multidimensional constructs to contrast them with relevant organizational learning models at the conceptual level. Following on the belief in the social nature of organizational learning especially when it pertains to tacit knowledge, the author classified the selected constructs whether they are founded on the technical or constructivist view. Among the technically driven constructs, Singh \& Gupta (2014) constructed and validated dimensions for knowledge management: Knowledge creation, sharing, retention and actionable knowledge support. Similarly, Santos-Vijande, López-Sánchez, and Trespalacios (2012) used a seven-point Likert scale questionnaire based on the following dimensions: (the acquisition of information, dissemination of knowledge, shared interpretation, and organizational memory )which were originally developed by Huber (1991) and modified by Slater and Narver (1995). Furthermore, Guţă (2014) founded an organizational learning model based on Huber (1991) technical construct but, while using exploratory factor analysis, she empirically constructed four relatively different components:

- Internal information/knowledge acquisition and information distribution,

- External information/knowledge acquisition and information interpretation

- Organizational memory, based on a codification strategy,

- Organizational memory, based on a personalization strategy

Other dimensions, while being parsimonious and too simplistic, suffered conceptual ambiguity such as the construct developed and used empirically by the research in high-tech companies (Hung et al., 2011) which used organizational learning and organizational culture as dimensions for organizational learning. Among the constructs that were founded on the social perspective of organizational learning is the one conducted by (Jyothibabu, Farooq, \& Pradhan, 2010) introduced seven dimensions for learning organizations which are:

- Continuous learning represents the organizational capability to sustain learning among its staff.

- Inquiry and dialogue encompass the organizational culture of critical thinking, feedback, and experimentation. 
- Team learning reflects the sense of collaboration.

- Employee empowerment entails the shared organizational vision and the engagement of staff in identifying gaps between actual versus planned vision.

- Embedded system indicates IT infrastructure that facilitates creating and sharing knowledge.

- System connection reflects extent to connect internal and external environments.

- $\quad$ Strategic leadership for learning

Hao, Kasper \& Muehlbacher, (2012) constructed organizational learning based on an open-minded commitment to learning, shared vision, openness experimentation, process and system's perspective. Additionally, Hult and Ferrel (1997) constructed and measured a scale for organizational learning for purchasing focused empirical study. The 23 items- scale was founded on conceptual models and theory and verified by experts panel review.

The proposed factors included:

- Team orientation: degree of team to learn and collaborate.

- Learning orientation: is the extent of organizations to focus on learning and how it relates to the performance.

- Memory orientation is when the shared knowledge gets retained in the organizational routines.

- Systems orientation: when the stakeholders embrace a holistic view of learning.

While comparing these socially driven constructs, the author emphasizes that they all dictate interactions between employees within the organization, yet, they miss to address the ontological and epistemological constituencies of organizational learning that formulate most of the social-based organizational learning theories that were mentioned in the previous section.

Among the constructs that addressed both the technical and social view while founding its dimensions on multiple organizational theories is the recent seminal work of Lloria \& Moreno-Luzon (2014). They constructed and validated a comprehensive 18 items scale for organizational learning which embodies five dimensions: the ontological levels of learning, modes of knowledge conversion, learning sub-processes, types of learning, and feedback and feed-forward flows of learning. This proposed model takes account of the concept, conditions, context, and processes of organizational learning using seven points Likert scale in the questionnaire. The study assessed reliability and validity using factor analysis. The study proposes four latent factors which proxied from variance- covariance analysis the whole construct:1) Information systems; 2) the existence of a framework for consensus; 3) procedures for the institutionalization and broadening of knowledge; and, finally, 4) forms of management and the genesis of knowledge. The ontological levels of learning are individual, group, organization and inter-organization (Nonaka, 1994). The modes of knowledge conversion are socialization, externalization, combination, and internalization (Nonaka, 1994). The learning sub-processes are: intuiting, interpreting, integrating and institutionalizing (Crossan et al., 1999). The types of learning are exploitation and exploration (March, 1991). The study also considers as well the feedback and feed-forward flows of learning (Bontis, Crossan, \& Hulland, 2002; Crossan et al., 1999). This multi-dimensional model comprehensively expresses several perspectives about organizational learning discipline and hence combines most of the seminal learning theories while manifesting the social, technical and the philosophical views of organizational learning (ontology and epistemology). Following on the TPS principles described earlier, the proposed dimensions by Lloria and Moreno-Luzon (2014) resonate with the six principles and with the overall learning, developing and improving axioms of the framework (Rampersad, 2003).

\subsection{Organizational Performance}

Organizational performance is not a singleton coherent construct. It is a consolidation of many organizational goals (Hirsch \&Levin, 1999), this belief utterly saps the unidimensionality of performance discipline in the following studies ( ( Jiménez-Jiménez et al., 2008; 2009; Lam et al., 2011) raising concerns about the robustness of the construct. The variability in the proposed dimensions for performance further complicates convergence efforts to determine an appropriate multidimensional model. Performance constructs often used subjective measurements perceived by key informants bypassing the difficulties in collecting actual objective measures from organizations. While perceived measures can be reasonably considered proxies of the objective measures of performance (Bontis et al., 2002), Shea, Cooper, De Cieri, \& Sheehan, (2012) rigorously evaluated perceived organizational performance scales using Rasch model analysis. Referring to their literature review conducted in prominent journals on perceptual measurements in organizational performance, only $34 \%$ of the studies performed CFA and EFA ( exploratory factor analysis) for construct validity. Half of the studies in organizational 
performance used unsupported scales as they failed to explain origin or reason of selection. Those studies which modified existing scales, 28\% used the scale of Delaney and Huselid (1996). Delaney and Huselid (1996) had 11 items in two dimensions (perceived organizational performance (seven items) and perceived market performance (four items).The paper found that the studied scale is psychometrically robust and serves as a second best alternative to objective measures. It seems that performance scales suffer significant deficiencies due to construct validity issues which complicate approaches to seek adequate multidimensional models. Agarwal, Erramilli, and Dev, (2003) and Guo (2002) formulated two dimensions for organizational performance: objective and judgmental. The objective dimension includes financial measures such as market share, growth, sales and profit while the latter includes the perceptions of staff and customers such as satisfaction and retention.

The study (Santos-Vijande et al., 2012) showed the impact of organizational learning on performance through efficient, competitive strategy and fitness to rapid market turbulence. They measured the performance via a market and financial indicators (sales, market share, and profits) and customer-related outcomes (customer satisfaction, loyalty, and value added perceptions). Customer performance includes eight items that assess: the firm's adaptability to customer needs and desires, the perceived added value (Vorhies \& Morgan, 2003) and the level of customer satisfaction (Hooley, Greenley, Cadogan, \& Fahy, 2005), the level of customer loyalty (Zahay \& Griffin, 2004), the communication achieved with customers, the reduction in the number of customer complaints, and the customer's perception of the firm's image. The measurement of business performance adopted sales growth (Greenley, 1995), market and profits. In the event of using financial performance, the return of asset ROA is widely used as an indicator of financial performance (Shropshire \& Kadlec, 2012).

As to innovation performance dimensions varied among researchers according to whether they should be objective or subjective. Objective indices include the number of patents obtained, reports published, market share and new projects approved while subjective indices include comparative indicators of quality and function of products with competitors ( Prajogo \& Sohal, 2003). Hao and his colleagues ( 2012) constructed the organizational performance based on financial (profit, return on investment) and non-financial characters (growth, market, and customer relationships) grounded on the work of several scholars (Panayides, 2007; Morales, Montes \& Jover, 2007).

Drawing on the diversity of the proposed dimensions for performance at the organizational level, the author highlights the commonality of the following dimensions: financial and non-financial performance, customer satisfaction and employees' performance. While financial performance measures the internal performance from any efficiency perspective, non-financial performance measures the organization effectiveness relatively to market competitiveness; finally, customer satisfaction measures the level of an interaction effect between the organization and its customers. The proposed dimensions significantly resonate with the personal, organizational competences of the TPS framework (Rampersad, 2003).

\subsection{Relationships between Organizational Learning and Quality}

The positive correlations between TQM and performance have been extensively documented in the literature (Dubey \& Gunasekaran, 2015; Demirbag et al., 2006; Prajogo \& Sohal, 2003). In parallel lines, the positive impact of organizational learning and performance was firmly demonstrated (Baker \& Sinkula, 1999; Bontis et al., 2002; Tippins \& Sohi, 2003\& Guță, 2014). Nevertheless, the mechanism by which organizational learning connects to TQM remains ambiguous. In fact, McAdam et al. (1998) conceptually examined the linkages between total quality and organizational learning contending that while both fields appear distinct, they shared common features. The study shed light on deficiencies for each area demonstrating the rationale to combine them to exercise a synergistic effect at a time where the distinct effects of TQM and organizational learning on performance have been extensively documented in the literature. Furthermore, it contends that TQM has focused on efficiency while organizational learning focused on proficiency. Hence, it stresses on the existing gap in literature and industry in exploring approaches that combine both fields.

Their analysis also showed that TQ (total quality) has often adopted the philosophy of mechanistic organizations while learning organization field ideologically assumed a living system. In parallel lines, learning organization as being in its infancy promises to be the primary focus TQM is attempting to converge to. Furthermore, following on the critical theory, they demonstrated that TQ assumed total commitment across all organization which is, in reality, is often restricted to senior management, from a change management view while TQM implies the acceptance of people towards changing roles and systems during the initiatives which is often not true in reality. Learning organization concepts as well suffered the assumption that unleashing the staff to their full potential secures a success which is too naive and simplistic as there would always be a need for a mechanistic control for alignment. The study calls for a holistic approach with a need for new techniques and 
tools to combine both fields in any change management project. Hence, the planned research aims to provide a basis for the development of such holistic approach

In fact, other scholars highlighted the pervading gap between continuous improvement and organizational learning on both conceptual and empirical levels (Sun, Ho, and Ni, 2008; Yoram, Rami, and Zvi, 1997). In the context of combining TQM and organizational learning in a single integrative model, Kumar (2012) argues that internationalization of TQM occurs using experiential learning which is facilitated by the action research methodology. Further, he states that organizational learning is a process similar to TQL (total quality learning). The study considers action learning as an organizational mechanism that institutionalizes learning while implementing TQM. Hence, the authors proposed action research as a cyclical experiential learning methodology that consists of 4 stages: plan, action, observe and reflect. The study demonstrates the similarities between PDCA and Action research by stating that Senge (1992) considers PDCA as an extension to Kolb (1984) and Lewin (1946); the very much authors of experiential learning and action research.

\section{Results}

The extensive literature review on the dimensions and the linkages between TQM, organizational learning and performance demonstrated the existence of a sound conceptual framework namely total performance scorecard (Rampersad, 2003) that underpins the integrity of the tripartite model. Despite the presence of diversified propositions about the dimensionality of each of the three constructs, the literature review unraveled the philosophical views of organizational learning (technical, social),TQM ( soft, hard practices) and performance ( efficiency, effectiveness) serving as a solid theoretical lens to address the appropriateness of the dimensions. Furthermore, the current review shed light on the current debate on how learning occurs during TQM activities.

Most of the proposed dimensions fell short to comprehensively combine, all together, the technical, human and managerial aspects of TQM. Furthermore, they have not offered adequate dimensions for organizational learning or any of its variants (e.g. organizational learning capability). The shortcomings in proposing appropriate and comprehensive dimensions anchor their roots through inabilities to simultaneously account for the epistemological and the ontological levels of learning, modes of knowledge conversion, learning sub-processes, types of learning, and feedback and feed-forward flow of learning.

Finally, neither their one-dimensional performance constructs nor their often bi-dimensional models appropriately attributed all the aspects of performance ( internal, external and interaction effect level).Additionally, while their findings converge to a single inference that TQM and organizational positively associate with performance with either partial or full mediation role of organizational learning, they overlooked other possible associations between components of each construct with the others at the micro le vel due to recurrent second order CFA practices. At the methodological level, whereas they conducted satisfactory reliability, models fit and validity studies, their CFA, when applied, lacked to appropriately report substantive statistical processes such as modification indices and the resultant measurement errors covariance operations while revising their models for an enhanced desirable model fit for each construct. Drawing on scales development, the selected studies partially missed to justify the rationale of their chosen scales, in the same vein, the development of the proposed dimensions for each construct relatively suffered a systematic approach and criticality of alternative dimensions from theoretical or philosophical viewpoints. In consideration of the multivariate analytical nature of the research studies in hand, the selected research articles often missed validating the normality of data or the adequacy of the samples which are crucial assumptions of SEM, CFA and even multiple regression techniques.

\section{Discussion}

Not too often, the selected articles have frequently sought to justify their chosen scales by linking to a theory, common conceptual grounds or even philosophical views. Furthermore, as an inevitable consequence of performing second -order CFA, the analyzed level of association confined its premises of analysis to only examine linkages between TQM, organizational learning, and performance making the possible interactions between the first -order dimensions of the three constructs inscrutable due to the overlay of the second-order dimensions. In this context, Lee and Cadogan (2013) found second order CFA practices invalid. Hence a parsimonious path analysis that connects the three constructs becomes futile in expounding how TQM and Organizational learning integrates into a single model operating synergistically on the performance of organizations. The interactions of the key components that define TQM with those of organizational learning serve as valuable indicators that would explain how organizational learning and TQM may function simultaneously. The proposed dimensions reflect strong connections with their relevant theoretical frameworks; consequently, they synchronize with the learning and quality principles of TPS framework (Rampersad, 2003). 
Hence, the current review offered a comprehensive theoretical background to understanding the linkages of the three constructs in the tripartite model. Other frameworks have been proposed to explain the learning mechanisms of quality practices. In fact, Sitkin, Sutcliffe, and Schueder (1994) findings that TQM consists of TQC (Total Quality Control) and TQL (Total Quality Learning) and consequently contends that TQL is embedded in TQL only if the latter is implemented based on philosophical view rather technical. The novelty of the current review, being the first to review the tripartite model, limits the discussions with similar research publications. Both TQL and TPS models share common backgrounds which confirm the synergy between learning and quality. Nevertheless, they differ in their structure. TPS framework is performance oriented while TQL embeds learning within the quality framework. Moreover, TPS principles account for the personal competence as integral for the performance improvement while TQL bounds its purview to the problem- solving solutions through PDCA. While both adopt PDCA cycle (Deming, 1986), TPS framework engages adaptive and generative learning; the latter does not appear to be firmly defined in TQL. Almatrooshi and Farouk (2016) proposed a performance framework which accounts for the leadership competencies as the main enabler to achieve organizational performance via the mediation of employee performance. The leadership competencies in that model are influenced by three antecedents: social, emotional and cognitive competencies. While this framework credits the role of leadership and workforce in improving performance, it overlooks the quality and learning attributes implying its unsuitability for the tripartite model.

Lloria and Moreno Luzon (2014) differentiate between knowledge creation (Nonaka, 1994 \& Crossan et al., 1999) from organizational learning theories (technical view) and the social views that derive the diversity of the currently published dimensions. March (1991) proposed learning types: exploitation and exploration. Therefore, it is suggested that the different perspectives that often spanned organizational learning fairly explain the observed diversity of dimensions. In the same vein, the abundance of quality management principles in literature reasonably explains the diversity of the proposed dimensions for TQM. Beckford (2002) provided a critical review of the reputable quality gurus' philosophies while acknowledging they all shared that quality entails measurement, assessment, and improvement. He critically considers Deming's14 principles (1986) to be too focused on the statistical control which is deemed challenging in the service sector as a service is instinctively intangible. This bold assumption means that TQM cannot be solely founded on technical approaches. In another setting, He critiques Juran's philosophy as being consistently dependent on management support at the account of workers' motivation. Furthermore, He critiques Oakland quality philosophy as being system - oriented focusing on the teamwork, training, and communication. This philosophy impulsively highlights the criticality of the dimension "workforce engagement. "Performance dimensions in the tripartite model often accounted for financial or nonfinancial dimensions while both contribute to the performance construct. Furthermore, the organizational performance includes customer satisfaction as a critical dimension.

\section{Limitations}

The limitations of this review are mainly due to a partial coverage the research linking TQM, organizational learning, and performance and a confined literature review to the dimensionality of the three constructs TQM, organizational learning, and performance. While recognizing differences between organizational learning and any of its variants (organizational learning capability) and differences between the variants of performance (organizational, market, innovation), the review accounted them all together while selecting the articles as the number of research articles that investigate the tripartite constructs is exiguous. This review could have included several studies that evaluated the failure while implementing separately TQM or organizational contrasting the findings with the conceptual linkages between TQM and organizational learning.

\section{Implications}

The review serves as a reference guide for appropriate dimensionality while designing research that examines the linkages between TQM, organizational learning, and performance. Furthermore, it calls upon a more detailed description of the findings while conducting confirmatory factor analysis.

The review further strengthens the growing evidence of the positive association between TQM, organizational learning, and performance as well as the possible mediation of organizational learning between TQM and performance.

For practitioners, the synergistic effect of TQM and organizational learning in leveraging performance has the potential to stimulate novel approaches in combining these two apparently distinct disciplines through innovative strategies and practices that integrate both concepts within a single framework. 


\section{Acknowledgements}

The author expresses gratitude towards the overwhelming contribution in the literature search and writing process of the professors at Swiss Business School in particular Professor Segeeta. Futhermore, a special appreciation to Dr Daria Chebotareva for her endeavor in refining and reviewing the English writing style and grammar.

\section{Abbreviations}

TQM: Total quality management

OLC: organizational learning capability

CFA: Confirmatory factor analysis

SEM: Structural equation modeling

\section{References}

Agarwal, S., Erramilli, M. K., \& Dev, C. S. (2003). Market orientation and performance in service firms: Role ofinnovation. Journal of Services Marketing, 17(1), 68-82. https://doi.org/10.1108/08876040310461282

Ahire, S. L., \& Golhar, D. Y. (1996). Quality management in large vs small firms. Journal of Small Business Management, 34(2), 1-11.

Al Ghamdi, A., Shah, F., Abd, B., Yusoff, R. Z., \& Mustafa, M. B. (2016). The Moderating Role of knowledge management on the relationship between employees 'commitment and total quality management: A Study on the public healthcare sector in Saudi Arabia, International Review of Management and Marketing, 6(4), 790-797.

Akgün, A. E., Ince, H., Imamoglu, S. Z., Keskin, H., \& Kocoglu, İ. (2014). The mediator role of learning capability and business innovativeness between total quality management and financial performance. International Journal of Production Research, 52(3), 888-901. https://doi.org/10.1080/00207543.2013.843796

Almatrooshi, B., Singh, S. K., \& Farouk, S. (2016). Determinants of organizational performance: a proposed framework. International Journal of Productivity \& Performance Management, 65(6), 844-859. https://doi.org/10.1108/JJPPM-02-2016-0038

Anderson, J. C., Rungtusanatham, M., \& Schroeder, R. G. (1994), A theory of quality management underlying the Deming management method, Academy of Management Review, 19(3), 472-509. https://doi.org/10.5465/AMR.1994.9412271808

Argyris, C., \& Schon, D. (1978). Organizational Learning: A theory of action perspective. Massachusetts: MA. Addison Wesley.

Bagozzi, R. P., \& Yi, Y. (1988). On the evaluation of structural equation model. Journal of the Academy of Marketing Science, 16(1), 74-94. https://doi.org/10.1007/BF02723327

Baiyin, Y., Watkins, K. E., \& Marsick, V. J. (2004). The Construct of the learning organization: Dimensions, measurement, and validation. Human Resource Development Quarterly, 15(1), 31-55. https://doi.org/10.1002/hrdq.1086

Bak, C. (1992), Lessons from veterans of TQM. Canadian Business Review, 19(4), 17-19.

Baker, W. E., \& Sinkula, J. M. (1999). The synergistic effect of market orientation and learning orientation on organizational performance. Journal of the Academy of Marketing Science, 27(4), 411. https://doi.org/10.1177/0092070399274002

Baldwin, J. R., \& Johnson, J. (1996), Business strategies in more and less innovative firms in Canada. Research Policy, 25(5). 785-804. https://doi.org/10.1016/0048-7333(95)00875-6

Bartlett, M. S. (1950). Tests of significance of factor analysis. British Journal of Psychology (Statistical Section), 3(77), 77-85. https://doi.org/10.1111/j.2044-8317.1950.tb00285.x

Beckford, J. (2002). Quality. London: Routledge, Taylor \& Francis Group.

Bertea, P., \& Zait, A. (2011). Methods for testing discriminant validity. Management \& Marketing-Craiova, 2, 217-224.

Black, S. E., \& Porter, L. J. (1996), Identification of the critical factors of TQM. Decision Sciences, 27(1), 1-21. https://doi.org/10.1111/j.1540-5915.1996.tb00841.x

Blackler, F. (1995). Knowledge, Knowledge work and organizations: An overview and interpretation, Organization Studies, 16(6), 1021-1046. https://doi.org/10.1177/017084069501600605 
Bontis, N., Crossan, M. M., \& Hulland, J. (2002), Managing an organizational learning system by aligning stocks and flows. Journal of Management Studies, 39(4), 437-469. https://doi.org/10.1111/1467-6486.t01-1-00299

Brown, T. (2015). Confirmatory Factor Analysis for Applied Research, $\left(2^{\text {nd }}\right.$ ed.), New York, NY: The Guilford Press.

Cangur, S., \& Ercan, I. (2015). Comparison of model fit indices used in structural equation modeling under multivariate normality. Journal of Modern Applied Statistical Methods, 14(1), 152-167.

Chen, F. (2007). Sensitivity of goodness of fit indexes to lack of measurement invariance. Structural equation modeling, 14(3), 464-504. https://doi.org/ 10.1080/10705510701301834

Crosby, P. B. (1996). Quality is Free, New York, NY: McGraw-Hill.

Crossan, M. M., Lane, H. W., \& White, R. E. (1999). An organizational learning framework: From intuition to institution. Academy Of Management Review, 24(3), 522-537. https://doi.org/10.5465/AMR.1999.2202135

Dean, J. W., \& Bowen, D. E. (1994). Management theory and total quality: Improvingresearch and practice through theory development. Academy of Management Review, 19(3), 392-418.

Delaney, J. T., \& Huselid, M. A. (1996). The impact of human resource management practices on organizational performance. Academy of Management Journal, 39(4), 949-969. https://doi.org/10.2307/256718

Deming, W. E. (1986). Out of crisis, Centre for Advanced Engineering Study. Massachusetts Institute of Technology, Cambridge, MA.

Demirbag, M., Tekinkus, L., Tatoglu, E., \& Zaim, S. (2006). TQM and market orientation's impact on SMEs' performance. Industrial Management \& Data Systems, 106(8), 1206-1228. https://doi.org/:10.1108/02635570610710836

Dubey, R., \& Gunasekaran, A. (2015). Exploring soft TQM dimensions and their impact on firm performance: some exploratory empirical results. International Journal of Production Research, 53(2), 371-382. https://doi.org/10.1080/00207543.2014.933909

Easterby-Smith, M., Araujo, L., \& Burgoyne, J. (1999). Organizational learning and the learning organization: Developments in theory and practice, Sage, London.

Easterby-Smith, M., \& Lyles, M. A. (2011). The evolving field of organisational learning and knowledge management. In M. Easterby-Smith \& M. A. Lyles (Eds.), Handbook of organizational learning \& knowledge management. Chichester: Wiley.

Evans, J. R., \& Lindsay, W. M. (1996). The management and control of quality. Minnesota: MN. West Publishing Company.

Flyyn, B. B., Schroder, R. G., \& Sakakibara, S. (1994). A framework for quality managementresearch and an associated measurement instrument. Journal ofOperations Management, 11(4), 339-366. https://doi.org/10.1016/S0272-6963(97)90004-8

Fornell, C., \& Larcker, D. F. (1981). Evaluating structural equation models with unobservable variables and measurement error. Journal of Marketing Research, 18(1), 39-50. https://doi.org/10.2307/3151312

Greenley, G. E. (1995). Market orientation and company performance: empirical evidence from UK companies. British journal of management, 6(1), 1-13. https://doi.org/ 10.1111/j.1467-8551.1995.tb00082.x

Gujarati, D. N. (1995). Basic econometrics. New York, NY: McGraw-Hill.

Guo, C. (2002). Market orientation and business performance: A framework for service organization. European Journal of Marketing, 36(9-10), 1154-1163. https://doi.org/10.1108/03090560210437389

Guţă, A. L. (2014). Measuring organizational learning . Model testing in two Romanian universities. Management \& Marketing Challenges for the Knowledge Society, 9(3), 253-282.

Hao, Q. M., Kasper, H., Muehlbacher, J., Wei, W. W., Hao, Q. M., Kasper, H., \& Muehlbacher, J. (2012). How does organizational structure influence performance through learning and innovation in Austria and China? Chinese Management Studies, 6(1),36-52. https://doi.org/10.1108/17506141211213717

Hoang, D. T., Igel, B., \& Laosirihongthong, T. (2006). The impact of total quality management on inno vation: findings from a de veloping country. International Journal of Quality and Reliability Management, 23(9), 1092-1117. https://dx.doi.org/10.1108/02656710610704230 
Hooley, G. J., Greenley, G. E., Cadogan, J. W., \& Fahy, J. (2005). The performance impact of marketing resources. Journal of Business Research, 58(1), 18-27. https://doi.org/10.1016/S0148-2963(03)00109-7

Hoyle, R. H., \& Panter, A. T. (1995). Writing about structural equation models. In R. H. Hoyle (Ed.), Structural equation modeling: Concepts, issues, and applications. Thousand Oaks, CA: Sage Publications.

Huber, G. P. (1991). Organizational learning: The contributing processes and the literatures.Organization Science, 2(1), 88-115. https://doi.org/10.1287/orsc.2.1.88

Hult, G. T. M., \& Ferrell, O. C. (1997). Global organizational learning capacity in purchasing: Construct and measurement. Journal of Business Research, 40(2), 97-111. https://doi.org/10.1016/S0148-2963(96)00232-9

Hung, R. Y. Y., Lien, B. Y. H., Yang, B., Wu, C. M., \& Kuo, Y. M. (2011). Impact of TQM and organizational learning on innovation performance in the high-tech industry. International Business Review, 20(2), 213-225. https://doi.org/10.1016/j.ibusrev.2010.07.001

Jiménez-Jiménez, D., Martinez-Costa, M., Martínez-Lorente, A. R., \& Rabeh, H. A. D. (2015). Total quality management performance in multinational companies Alearning perspective. TQM Journal, 27(3), 328-340. https://doi.org/10.1108/TQM-01-2014-0002.

Jöreskog, K. G.,\& Sörbom, D. (1996). LISREL 8 User's Reference Guide, Scientific Software International, Chicago.

Juran, J. M. (1988). Juran on planning for quality, New York, NY: Free Press.

Jyothibabu, C., Farooq, A., \& Pradhan, B. B. (2010). An integrated scale for measuring an organizational learning system. Learning Organization, 17(4), 303-327. https://doi.org/10.1108/09696471011043081

Kaiser, H. F. (1974). An index of factorial simplicity. Psychometrika, 39(1), 31-36. https://doi.org/10.1007/BF02291575

Kline, R. B. (2011). Principles and practice of structural equation modeling, (3rded.) New York, NY: The Guilford Press.

Kolb, D. A. (1984). Experiential learning: Experience as the source of learning and development. New Jersey: Prentice Hall.

Lam, S. Y., Lee, V. H., Ooi, K. B., \& Lin, B. (2011). The relationship between TQM, learning orientation and market performance in service organisations: An empirical analysis. Total Quality Management \& Business Excellence, 22(12), 1277-1297. https://doi.org/10.1080/14783363.2011.631337

Lau, R. S. M., \& Anderson, C. A. (1998). A three-dimensional perspective of total quality management, International Journal of Quality and Reliability Management, 15(1), 85-98. https://doi.org/10.1108/02656719810199277

Lee, N., \& Cadogan, J. W. (2013). Problems with formative and higher-order reflective variables. Journal of Business Research, 66(2), 242-247. https://doi.org/10.1016/j.jbusres.2012.08.004

Lee, H. H., \& Lee, C. Y. (2014). The effects of total quality management and organisational learning on business performance: evidence from Taiwanese insurance industries. Total Quality Management \& Business Excellence, 25(9-10), 1072-1087. https://doi.org/10.1080/14783363.2013.814291

Lewin, K. (1946). Action research and minority problems. Journal of social issues, 2(4), 34-46. https://doi.org/10.1111/j.1540-4560.1946.tb02295.x

Lin, B., Ogunyemi, F. (1996). Implications of total quality management in federal services: The US experience. International Journal of Public Sector Management, 9(4), 4-11. https://doi.org/10.1108/09513559610128654

Lloria, M. B., \& Moreno-Luzon, M. D. (2014). Organizational learning: Proposal of an integrative scale and research instrument. Journal of Business Research, 67(5), 692-697. https://doi.org/10.1016/j.jbusres.2013.11.029

MacCallum, R. C., Browne, M. W., \& Sugawara, H. M. (1996). Power analysis and determination of sample size for covariance structure modeling. Psychological methods, 1(2), 130-149. https://doi.org/10.1037/1082-989X.1.2.130

Mahmood, S., Qadeer, F., \& Ahmad, A. (2015). The role of organizational learning in understanding relationship between total quality management and organizational performance. Pakistan Journal of Commerce \& 
Social Sciences, 9(1), 282-302.

March, J. G. (1991). Exploration and exploitation in organizational learning. Organization science, 2(1), 71-87. https://doi.org/10.1287/orsc.2.1.71

Martínez-Costa, M., \& Jiménez-Jiménez, D. (2008). Are companies that implement TQM better learning organisations? An empirical study. Total Quality Management \& Business Excellence, 19(11), 1101-1115. https://doi.org/10.1080/14783360802323446

Martínez-Costa, M., \& Jimenez-Jimenez, D. (2009). The Effectiveness of TQM The Key Role of Organizational Learning in Small Businesses. International Small Business Journal, 27(1), 98-125. https://doi.org/10.1177/0266242608098348

McAdam, R., Leitch, C., Harrison, R., Wang, C. L., Ahmed, P. K., Coronado, R. B., \& Antony, J. (1998). Thelinksbetween organisational learning and total quality: a critical review. Journal of European Industrial Training, 22(2), 47-56. https://doi.org/10.1108/03090599810204299

Morales, V. J., Montes, F. J., \& Jover, A. J. (2007). Influence of personal mastery on organizational performance through organizational learning and innovation in large firms and SME. Technovation, 27(9), 547-568. https://doi.org/10.1016/j.technovation.2007.02.013

Mosadeghrad, A. M. (2014).Why TQM programmes fail? A pathology approach. The TQM Journal, 26(2), 160-187. https://doi.org/10.1108/TQM-12-2010-0041

Munizu, M. (2013). The Impact of total quality management practices towards competitive advantage and organizational performance: Case of fishery industry in South Sulawesi Province of Indonesia. Pakistan Journal of Commerce and Social Sciences, 7(1), 184-197.

Neve, T. O. (2015). Eight Steps to Sustainable Organizational Learning: How to Tackle Search and Transfer Barriers. https://doi.org/10.1007/978-3-319-15937-9 ISSN

Nonaka, I. (1994). A dynamic theory of organizational knowledge creation. Organization Science, 5(1), 14-37. https://doi.org/10.1287/orsc.5.1.14

Ortenblad, A. (2015). Towards increased relevance: context-adapted models of the learning organization. Learning Organization, 22(3), 163-181. https://doi.org/10.1108/TLO-06-2014-0027

Podsakoff, P. M., MacKenzie, S. B., Lee, J., \& Podsakoff, N. P. (2003). Common method biases in behavioral research: A critical review of the literature and recommended remedies. Journal Of Applied Psychology, 88(5), 879-903. https://doi.org/10.1037/0021-9010.88.5.879

Prajogo, D. I., Power, D. J., \& Sohal, A. S. (2004). The role of trading partner relationships in determining innovation performance: An empirical examination. European Journal of Innovation Management, 7(3), 178-186. https://doi.org/10.1108/14601060410549874

Prajogo, D. I., \& Sohal, A. S. (2003). The relationship between TQM practices, quality performance and innovation performance. The International Journal Of Quality Reliability Management, 20(8), 901-918. https://doi.org/10.1108/02656710310493625

Prajogo, D. I., \& Sohal, A. S. (2006), The relationship between organization strategy, total quality management (TQM), and organization performance - the mediating role of TQM. European Journal of Operational Research, 168(1). 35-50. https://doi.org/10.1016/j.ejor.2004.03.033

Panayides, P. M. (2007). The impact of organizational learning on relationship orientation, logistics service effectiveness and performance. Industrial Marketing Management, 36(1), 68-80. https://doi.org/10.1016/j.indmarman.2005.07.001

Rampersad, H. K. (2003). Total performance scorecard: Redefining management to achieve performance with integrity. Amsterdam ; Butterworth-Heinemann. https://doi.org/10.1016/b978-0-7506-7714-1.50007-1

Richard, P. J., Devinney, T. M., Yip, G. S., \& Johnson, G. (2009). Measuring organizational performance: Towards methodological best price. Journal of Management, 35(3), 718-804. https://doi.org/10.1177/0149206308330560

Santos-Vijande, M. L., López-Sánchez, J. Á., \& Trespalacios, J. A. (2012). How organizational learning affects a firm's flexibility, competitive strategy, and performance. Journal of Business Research, 65(8), 1079-1089. https://doi.org/10.1016/j.jbusres.2011.09.002

Schinka, J. A., Velicer, W., Weiner, F., \& Irving, B. (2003). Handbook of psychology: Research methods in 
psychology, John Wiley and Sons.

Senge, P. M. (1992). The Fifth Discipline: The Art and practice of the learning organization, London, Century Business.

Shea, T., Cooper, B. K., De Cieri, H., \& Sheehan, C. (2012). Evaluation of a perceived organisational performance scale using Rasch model analysis. Australian Journal of Management, 37(3), 507-522. https://doi.org/ 10.1177/0312896212443921

Shropshire, J., \& Kadlec, C. (2012). Where are you going? A comparative analysis of job and career change intentions among USA it workers. Journal of Internet Banking and Commerce, 17(2), 1-20. https://doi.org/10.1002/job

Sitkin, S. B, Sutcliffe, K. M., \& schueder, R. G. ( 1994). Distinguishing control from learning in total quality management: a contingency perspective. Academy of Management Review, 19(3), 537-564. https://doi.org/10.5465/AMR.1994.9412271813

Singh, R. M., \& Gupta, M. (2014). Knowledge management in teams: empirical integration and development of a scale 136728 . Journal of Knowledge Management, 18(4), 777-794. https://doi.org/10.1108/JKM-11-2013-0450

Slater, S. F., \& Narver, J. C. (1995). Market orientation and the learning organization. Journal of Marketing; 59(3), 63-74.

Hongyi, S., Kario, H., \& Wenbin, N. (2008). The empirical relationship among organizational learning, continuous improvement and performance improvement. International Journal of Learning and Change, 3(1), 110-124. https://doi.org/10.1504/IJLC.2008.018871

Terziovski, M., \& Samson, D. (1999). The link between total quality management practice and organizational performance. International Journal of Quality \& Reliability Management, 16(3), 226-237. https://doi.org/10.1108/02656719910223728

Their, S. (2000). Att leda l€arande och f€or€andring. Helsingfors: Pro Futura Ab Oy.

Thorpe, R., \& Holloway, J. (2000). Performance management: Multidisciplinary perspectives, Palgrave Mcmillan. https://doi.org/10.1057/9780230288942

Tippins, M. J., \& Sohi, R. S. (2003). IT competency and firm performance: Is organizational learning a missing link? Strategic Management Journal, 24(8), 745-761. https://doi.org/10.1002/smj.337

Trussler, S. (1998). The rules of the game. Journal of Business Strategy, 19(1), 16-19. https://doi.org/10.1108/eb039904

Vorhies, D. W., \& Morgan, N. A. (2003). A Configuration Theory Assessment of Marketing Organization Fit with Business Strategy and Its Relationship with Marketing Performance. Journal of Marketing, 67(1), 100-115. https://doi.org/10.1509/jmkg.67.1.100.18588

Wall, T. D., Michie, J., Patterson, M., Wood, S. J., Sheehan, M., Clegg, C. W., \& West, M. (2004). On the validity of subjective measures of company performance. Personnel Psychology, 57(1), 95-117. https://doi.org/10.1111/j.1744-6570.2004.tb02485.x

Weerawardena, J., O'Cass, A., \& Julian, C. (2006). Does industry matter? Examining the role of industry structure and organizational learning in inno vation and brand performance. Journal of Business Research, 59(1), 37-45. https://doi.org/10.1016/j.jbusres.2005.02.004

Yoram, M. A. B., Rami, S., \& Zvi, M. (1997). Organizational learning mechanisms and continuous improvement: A longitudinal study. Journal of Organizational Change Management, 10(5), 426-446. https://doi.org/10.1108/09534819710177530

Zahay, D., \& Griffin, A. (2004). Customer learning processes, Strategy selection, and performance in $\begin{array}{lllll}\text { business-to-business service firms. Decision } & \text { Sciences, }\end{array}$ https://doi.org/10.1111/j.00117315.2004.02338.x

Zairi, M. (2013). TheTQM legacy - Gurus' contributions and theoretical impact. The TQM Journal, 25(6), 659-676. https://doi.org/10.1108/TQM-06-2013-0069

Zeitz, G., Johannesson, R., \& Ritchie Jr., J. E. (1997). An employee survey measuring total quality managementpractices and culture. Group \& Organization Management, 22(4), 414-444. https://doi.org/10.1177/1059601197224002 


\section{Appendices}

Appendix A: Scale characteristics of the selected articles

\begin{tabular}{ccc}
\hline Article & Sample Size /Likert scale & Response rate \\
\hline (Hung et al., 2011) & 223 & $19.6 \%$ \\
(Akgün et al., 2014) & 193 & $42 \%$ \\
(Mahmood, Qadeer and Ahmad, 2015) & 270 & $46 \%$ \\
(Lee \& Lee, 2014) & 850 & $89.47 \%$. \\
(Jiménez-Jiménez et al., 2015) & 444 & Not reported \\
(Lam et al., 2011) & 146 & $29.2 \%$ \\
(Martínez-Costa \& Jiménez-Jiménez, 2008) & 451 & $43.8 \%$. \\
(Martínez-Costa \& Jimenez-Jimenez, 2009) & 706 & $45.4 \%$ \\
\hline
\end{tabular}

Appendix A: scales of selected articles

\section{Copyrights}

Copyright for this article is retained by the author(s), with first publication rights granted to the journal.

This is an open-access article distributed under the terms and conditions of the Creative Commons Attribution license (http://creativecommons.org/licenses/by/4.0/). 